Eixo Temático: Relação entre Ciência, Educação e Cultura

\title{
ET-05-006 \\ CONSCIENTIZAÇÃO AMBIENTAL: O VERDADEIRO COMBATE AO DENGUE, CHINCUNGUNYA E ZIKA VÍRUS, UM ESTUDO EM UM COLÉGIO ESTADUAL NO MUNICÍPIO DE SALVADOR-BA.
}

Diele Gonçalves Santos¹, Juma Gomes da Silva²

${ }^{1}$ Bolsista ID PIBID-UNEB/CAPES. Universidade do Estado da Bahia. DCET II - Campus de Alagoinhas. Rod. Alagoinhas-Salvador, BR 100, KM 03, CEP 48040-210. E-mail: mel.haney@hotmail.com.br, dieliysantos@hotmail.com.

${ }^{2}$ Colégio Estadual Professor Edson Carneiro. São Ceatano. Salvador-BA. PIBIDUNEB/CAPES. Universidade do Estado da Bahia. DCET II - Campus de Alagoinhas. Rod. Alagoinhas-Salvador, BR 100, KM 03, CEP 48040-210.

http://dx.doi.org/10.21472/congrebio2016.et-05-006

\section{RESUMO}

Essa pesquisa trata-se de assuntos atuais: a Dengue, a Chinkungunya e o Zika vírus. Doenças que tem atingido não só a classe baixa, como também a média e a alta. Todos estão sujeitos a adquiri-la; onde o processo de conscientização e combate ao mosquito pode fazer com que esta epidemia possa ser abolida da vida da população e do meio ambiente. Levando-se em consideração a epidemia do dengue que assola o país e o elevado índice de aumento dos casos de Chikungunya, Zika vírus, surgiu à inquietação de fazer um levantamento de como anda o nível de conscientização dos alunos do $2^{\circ}$ ano do ensino médio, turno matutino, do Colégio Estadual Professor Edson Carneiro, no bairro de São Caetano, Salvador-Ba, quanto à prevenção do arbovirus, conscientização e eliminação de criadouros de mosquito no ambiente doméstico, além de engajar ativamente os alunos da educação estadual nesta problemática. Esta pesquisa é caráter qualitativo e quantitativo. Para o levantamento de dados, foram entregue aos 80 alunos, um questionário contendo 20 questões e um panfleto exemplificativo de combate aomosquito da dengue, concedido pela Unidade de Emergência de São Caetano. Estas informações foram dispostas em gráficos e tabelas, no programa Excel, e em seguida foram analisadas, permitindo que os resultados da pesquisa fossem alcançados. Como subsídios de embasamento foram realizados pesquisa em livros, sites e panfletos exemplificativos. Os resultados obtidos revelaram que $89 \%$ dos alunos moram no mesmo bairro da escola. $73 \%$ dos entrevistados revelaram que quando apresentaram sintomas suspeitos de algumas dessas doenças, fizeram uso de medicamentos por conta própria e $27 \%$ não se automedicaram. Quanto à identificação do mosquito Aedes aegypti, 86\% declararam que sabem identificar o mosquito e $14 \%$ não. Relacionado ao combate do mosquito Aedes aegyptie no que diz respeito a ações que previnam os focos de reprodução, $100 \%$ dos entrevistados disseram que o país pode contar com a sua participação, sendo nulo o numero de pessoas com que não se propuseram a acabar com os focos de água parada. O espaço escolar é um ótimo meio de difusão de informações. Este estudo considera que a ação de combate ao mosquito, envolvendo a comunidade escolar, é de grande relevância. Pois os alunos trabalharam como agentes protagonistas no controle da proliferação do mosquito e de conscientização das doenças relacionadas. Mudar atitudes requer uma nova atuação. É importante sensibilizar os alunos e as pessoas, espalhar e socializar conhecimentos entre os diversos grupos sociais, pois a educação ambiental deve ser efetuada de forma continua e permanente. Por fim conclui-se queo mosquito não é mais forte que um país inteiro.

Palavras-chave: Conscientização ambiental; Aedes aegypti; Escola. 


\section{INTRODUÇÃO}

A escola é um ambiente de diversas atividades, inclusive á saúde. Educação em saúde é um tema que tem sido trabalho na atualidade por diversos autores, pois este é um meio legitimo de proporcionar a uma parcela significativa da população à tomada de decisões em prol da saúde pública.

O espaço escolar permite que se investiguem diversos temas relacionados à saúde, em especial aqueles que contemplam também questões relacionadas ao meio ambiente. Um dos temas que pode ser abordado nas escolas é "Conscientização ambiental: o verdadeiro combate ao dengue, chincungunya e zika vírus”, uma vez que, os casos de dessas doenças tem aumentado no país.

Segundo Narcizo (2009), educadora ambiental, a escola é o espaço social e o local onde o aluno dará sequência ao seu processo de socialização iniciado em casa com seus familiares. Considerada toda a importância da temática ambiental se sobressaem às escolas como espaços privilegiados no desenvolvimento socioambiental dos alunos.

A partir disso, surgiu à inquietação trabalhar este tema e fazer um levantamento sobre o nível de conscientização dos alunos do $2^{\circ}$ ano do ensino médio, da Escola Estadual professor Edson Carneiro, no bairro de São Caetano, Salvador-Ba, quanto à prevenção do mosquito Aedes aegypti. Focar quanto à importância da eliminação de criadouros no ambiente doméstico, discussão sobre o tema com os familiares, além de engajar ativamente os alunos da educação estadual na problemática da dengue, chikungunya e zika vírus.

Dengue, zika e chikungunya são doenças transmitidas pormosquitos (arboviroses) Aedes aegypt e Aedes albopctus, mosquitos que há cerca de 30 anos são conhecidos pelas epidemias anuais de dengue no Brasil. Nos últimos meseso país começou a registrar casos da febre zika e da febre chikungunya que, além da transmissão, também tem nos sintomas características semelhantes, mas com peculiaridades preocupantes. Apesar de serem doenças diferentes, a forma de prevenção é a mesma: evitar a proliferação do mosquito, ou seja, erradicar locais de acúmulo de água parada. Se os criadouros não forem destruídos, além da dengue, há grandes chances de que haja uma epidemia de chikungunya no Brasil.

A dengue é a mais conhecida e presente no Brasil. É uma enfermidade causada por um vírus de genoma RNA pertencente ao grupo B dos arbovírus, Família Flaviviridae, gênero Flavivirus (BASTOS, 2001). Este vírus é transmitido para uma pessoa saudável através da picada da fêmea contaminada do mosquito Aedes aegypti. Clinicamente, as manifestações variam de uma síndrome viral, inespecífica e benigna, até um quadro grave e fatal de doença hemorrágica com choque. São fatores de risco para casos graves: a cepa do sorotipo do vírus infectante, o estado imunitário e genético do paciente, a concomitância com outras doenças e a infecção prévia por outro sorotipo viral da doença (TRAVASSOS DA ROSA et al., 1998 apud BASTOS, 2004).

Sabe-se que os 4 tipos conhecidos de vírus da dengue são potencialmente graves e fatais. Esse potencial de gravidade aumenta, expressivamente, em uma segunda infecção por novo sorotipo que, eventualmente, penetre na mesma comunidade, concomitante ou sucedendo ao primeiro (MARZOCHI).

Esta doença pode se manifestar de duas maneiras: a dengue clássicaque apresenta febre alta, dores de cabeça, nas costas e na região atrás dos olhose a dengue hemorrágica com hemorragia em vários órgãos do corpo, choque circulatório, vômitos, tontura, dificuldades de respiração, dores abdominais fortes e contínuas, presença de sangue nas fezes e em alguns casos falecimento.

Já a febre de chikungunya é uma arbovirose causada pelo vírus chikungunya (CHIKV), da família Togaviridae e do gênero Alphavirus. A viremia persiste por até dez dias após o surgimento das manifestações clínicas. A transmissão ocorre pela picada de fêmeas dos mosquitos Aedes Aegypti e Aedes albopictus infectadas pelo CHIKV. Casos de transmissão vertical podem ocorrer quase que, exclusivamente, durante o período de intraparto em gestantes 
virêmicas e, muitas vezes, provoca infecção neonatal grave. Pode ocorrer transmissão por via transfusional, todavia é rara se os protocolos forem observados.

Os sinais e os sintomas são clinicamente parecidos com os da dengue - febre de início agudo, dores articulares e musculares, cefaleia, náusea, fadiga e exantema. A principal manifestação clínica que as difere são as fortes dores nas articulações. Após a fase inicial, a doença pode evoluir em duas etapas subsequentes: fase subaguda e crônica. Embora o chikungunya não seja uma doença de alta letalidade, tem caráter epidêmico com elevada taxa de morbidade associada à artralgia persistente, tendo como consequência a redução da produtividade e da qualidade de vida.

E o zica vírus foi descoberto em 1947, porém tem assolado no Brasil atualmente. Sendo isolado pela primeira vez, a partir de um macaco Rhesus, na floresta Zica, em Uganda, na África. O vírus zika é um flavivírus (Família Flaviviridae) transmitido por Aedes aegypti e que foi originalmente isolado de uma fêmea de macaco Rhesus febril na Floresta Zika (daí o nome do vírus), localizada próximo de Entebbe na Uganda, em 20 de abril de 1947. Esse vírus é relacionado ao VFA e dengue, também transmitidos por Aedes aegypti e que causam febre hemorrágica.

O vírus zica tem causado doença febril, acompanhada por discreta ocorrência de outros sintomas gerais, tais como cefaleia, exantema, mal estar, edema e dores articulares, por vezes intensas. No entanto, apesar da aparente benignidade da doença, mais recentemente na Polinésia Francesa e no Brasil, quadros mais severos, incluindo comprometimento do sistema nervoso central (síndrome de Guillain-Barré, mielite transversa e meningite), e má formação do cérebro (microcefalia) dos bebes recém-nascidos, durante a gestação, associados ao zika têm sido comumente registrados, o que mostra quão pouco conhecida ainda é essa doença. Reconhecida quase simultaneamente, em fevereiro de 2015 na Bahia a circulação da doença causada pelo vírus zika foi rapidamente confirmada pelo uso de métodos moleculares. Há possibilidade do vírus poder ser transmitido por sangue e hemoderivados, os primeiros registros foicontatado em um paciente que recebeu transfusão sanguínea contaminada de um doador em período de incubação, em um paciente no Rio de Janeiro e na Bahia.

Estas doenças infecciosas são transmitidas pela fêmea do mosquito Aedes aegypti, que necessita da albumina, substância encontrada no sangue, para completar o processo de amadurecimento de seus ovos. O vetor apenas transmite o vírus, mas não seus efeitos. Esta põe ovos de 4 a 6 vezes durante sua vida, podendo colocar mais de 100 ovos de cada vez, em locais preferencialmente com água limpa e parada. O Aedes aegypti costuma picar as pessoas durante o dia 5.

O ciclo se inicia quando a fêmea do Aedes aegypti pica uma pessoa com dengue. O tempo necessário para o vírus se reproduzir no organismo do mosquito é de 8 a 12 dias. Após isso, ele começa a transmitir o vírus causador da doença. Esse mesmo mosquito, ao picar um ser humano sadio, transmite o vírus para o sangue dessa pessoa. Dentro de um tempo, que varia de 3 a 15 dias, a doença começa a se manifestar. A partir daí o ciclo pode voltar a se repetir, caso essa segunda pessoa seja picadapor outro Aedes aegypti. O ciclo do mosquito transmissor apresenta quatro fases: ovo, larva, pupa e adulto.

É indispensável que as ações para o controle dessas doençasgarantam a participação efetiva de cada moradorda comunidade na abolição de criadouros jáexistentes ou de possíveis locais para reprodução domosquito. É seguro que atitudes simples de educação ambiental, podem ajudar no controle e combate do mosquito. Para tanto, atitudes devem ser analisadaspela população para que assim possam ajudar a reduzira incidência de casos de doenças. Atentandose aos detalhes, como por exemplo: descartar o lixo em locais corretos; cuidar diariamente dos vasos de plantas; tampar corretamente as caixas d'água; limpar terrenos baldios e os quintais das residências abandonadas, entre outras ações.

Este assunto tem gerado discussão e tem causado um maior impacto na saúde pública. $\mathrm{O}$ controle destas doenças tipicamente urbanassãocomplexas, envolvendo, além do setor saúde, fatores como infraestrutura das cidades, transporte de pessoas e cargas, o meio ambiente, entre outros. 
Segundo Chiaravalloti Neto (1997) as "atividades de eliminação de criadouros (...) não têm se mostrado suficientes para diminuir os níveis de infestação do mosquito, já que os recipientes eliminados têm sido sistematicamente substituídos”. A explosão de número de recipientes artificiais, tais como plásticos em geral, pneus e o hábito de cultivar plantas em vasos com água vem corroborando este acúmulo indevido de materiais passíveis de se tornarem criadouros do mosquito.

Compreende-se que as ações públicas para o combate do problema aumentaram, agrupandoprocedimentos que estão voltados á mobilização social e também ações voltadas ao controle químico do vetor. Há o reconhecimento que ações educativas podem diminuir significativamente os focos do mosquito. Informando a população que as suas mudanças de atitudes são de extrema importância para o combate a essas doenças.

A escola é uma instituição que representa uma parcela significativa da comunidade em que está inserida, tendo responsabilidade de integrar e gerar novas perspectivas, ampliando o trabalho educativo voltado às questões de saúde, procurando desenvolver atividades que mobilizem a comunidade na tomada de ações que diminuam a ocorrência dos vetores no meio.

\section{METODOLOGIA}

Esta pesquisa é de caráter qualitativo e quantitativo. Para o levantamento de dados, foram entregue aos 78 alunos, do $2^{\circ}$ ano, turmas $A / B$ do ensino médio, turno matutino, um questionário contendo 20 questões e um panfleto exemplificativo de combate de combate ao mosquito da dengue, concedido pela Unidade de Emergência de São Caetano. Estes levaram para casa e responderem juntamente com seus pais, além de realizar observações em sua residência ou perto dela, referentes ao acumulo de criatórios de água parada. Estas informações foram dispostas em gráficos e tabelas, no programa Excel, e em seguida foram analisadas, permitindo que os resultados da pesquisa fossem alcançados. Como subsídios de embasamento foram realizados pesquisa em livros, sites e panfletos exemplificativos.

\section{RESULTADOS}

Os resultados revelaram que $89 \%$ dos alunos moram no mesmo bairro do colégio e $11 \%$ em bairros vizinhos. Quanto ao questionamento se algum familiar já teve dengue, chinkungunya ou zika vírus, 70\% responderam que sim e 30\% disseram que não, como mostra o Gráfico 1.

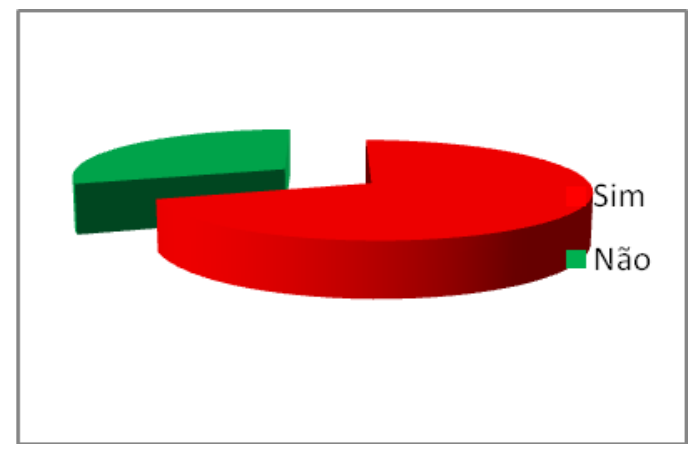

Grafico 1. Familiar que já teve dengue, chinkungunya ou zika vírus.

Do total de entrevistados, $40 \%$ revelaram que quando apresentaram algumas destas doenças procuraram ajuda do médico e $60 \%$ não procuraram atendimento. E que $73 \%$ destes, fizeram o uso de medicamentos por conta própria, $27 \%$ declaram não se medicar. Quanto à identificação do mosquito Aedes aegypti, 86\% declarou que sabe identificar e 14\% declaram não saber. 


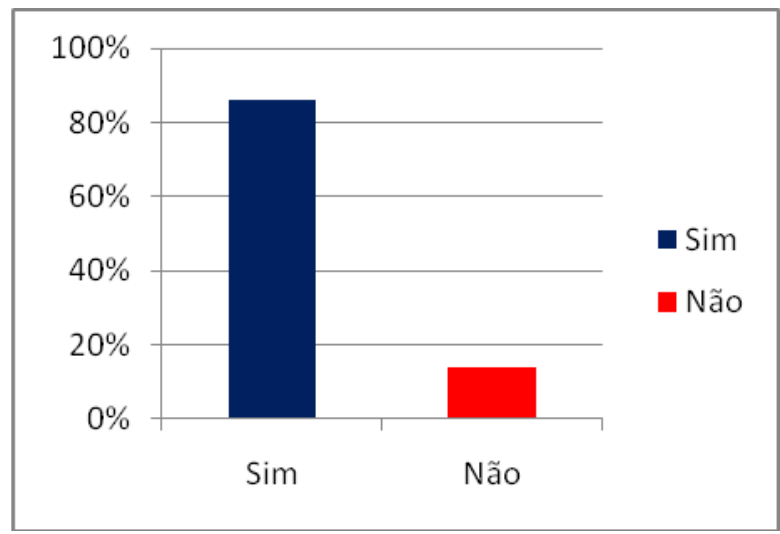

Gráfico 2. Identificação do mosquito Aedes aegypti.

Questionados se já encontraram o mosquito Aedes aegypti em sua residência ou próxima dela, $69 \%$ disseram que já encontraram o mosquito de cor preta com listras brancas e $31 \%$ disseram que não. A análise dos dados demonstrou que $80 \%$ dos entrevistados recebem visitas dos agentes de endemias e $20 \%$ ainda não receberam o agente em sua casa. É de extrema importância abordar que $85 \%$ dos entrevistados disseram que o meio mais seguro de combater a essas doenças é a prevenção do mosquito e 15\% deles não opinaram, como mostra no Gráfico 3.

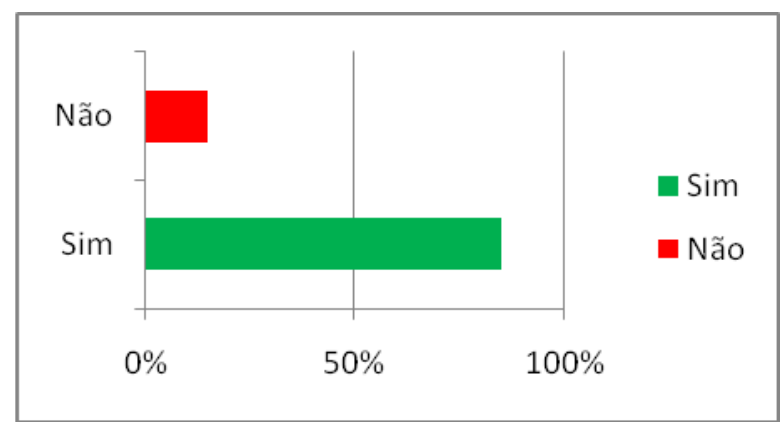

Gráfico 3. O meio mais seguro para o combate das doenças.

Quanto à pergunta se no próprio domicilio tinha recipientespotenciais para a criação do mosquito $28 \%$ disseram que sim e $72 \%$ declararam que não. Referente ao combate do mosquito Aedes aegypti e no que diz respeito a ações que previnam os focos de reprodução, $100 \%$ dos entrevistados disseram que o país pode contar com a sua participação, sendo nulo o numero de pessoas que se opõem, como pode ser observado no Gráfico 4.

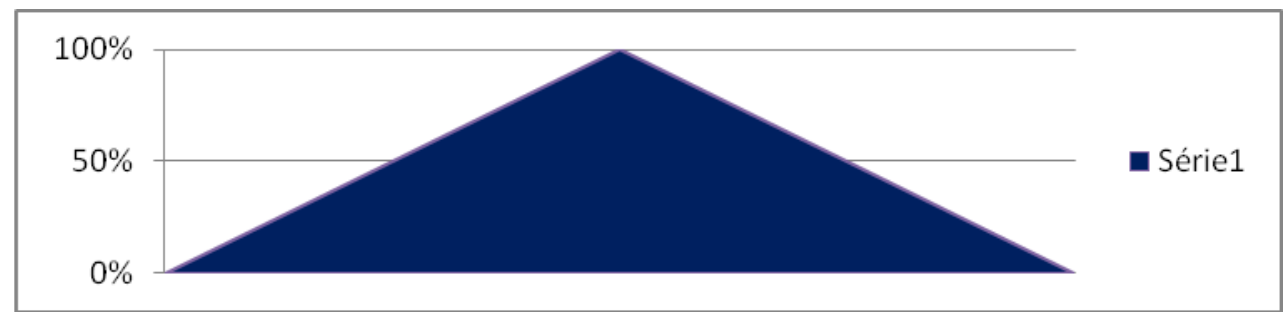

Gráfico 4. O país pode contar com você para o combate da proliferação do mosquito? 


\section{DISCUSSÃO}

A dengue, chinkungunyae o zika vírus estão vinculados diretamente saneamento doméstico, já que $90 \%$ dos focos do mosquito encontram-se nas residências. Este trabalho demonstrou-se de grande importância, pois o objetivo de sensibilização dos alunos e de sua família para o combate ao mosquito Aedes aegypti foi alcançado. Em suma, a educação ambiental pode mudar o mundo. O ser humano tem que acreditar no seu poder de transformaçãoe fazer de tudo pra viver melhor e livre dessas doenças que tem atingido milhões de pessoas em todo o Planeta Terra.

\section{CONCLUSÃO}

Enfim, é valido ressaltar a precisão de aperfeiçoar o controle vetorial no município quanto à infestação do Aedes aegypti, já que somente essa espécie no Brasil está, até o momento, associada à transmissão de três arboviroses, dengue, chikungunya e zika e, também, o enorme desafio da vigilância epidemiológica em adotar precocemente as novas áreas com transmissão para diminuir o impacto dessas doenças na população.

Percebe-se que a Educação Ambiental deve ser empregada para reforçar o modo de pensar e de atuar no meio ambiente da escola e da sociedade.

É necessário sensibilizar e conscientizar os alunos e as pessoas, difundir e socializar informações entre os diversos grupos sociais, gerando e promovendo o conhecimentopara gerar novas atitudes, novo valores em relação ao meio e novo comportamento diante da sociedade, viabilizando uma releitura do mundo e de sua realidade, de forma a perceber a dinâmica sócioambiental que relaciona o global e o local.

O combate à reprodução do mosquito transmissores das doenças dengue, chinkungunya e o zika vírus dependem de todos. Não manter água parada é o principal meio de prevenção.

Por meio deste trabalho buscou-se refletir a educação ambiental em seus diversosaspectos, seja na Educação formal ou não formal, pois ela não é bipartida, e sim única, podendo diferenciar-se apenas onde é realizada, se em um ambiente formal ou informal. Mudar atitudes requer uma nova atuação. Esta nova atuação pode ser alcançada através de atividades que a desenvolvam e a valorizam o meio ambiente.

\section{REFERÊNCIAS}

A escola construindo caminhos para a Sustentabilidade. Disponível em $<$ http://caminhosparaasustentabilidade.blogspot.com.br>. Acesso: 01 mar. 2016.

AMARAL, W. A Educação ambiental e a consciência da solidariedade ambiental.

CAMPOS, G. S.; BANDEIRA, A. C.; SARDI, S. I. Zika virus outbreak, Bahia, Brazil. Emerg. Infect. Dis., v. 21, n. 10, p. 1-5, 2015.

MINISTÉRIO DA SAÚDE. Dengue: aspectos epidemiológicos, diagnóstico e tratamento. Brasília: Fundação Nacional de Saúde, 2002. (Série A. Normas e Manuais Técnicos, $\mathrm{n}^{\circ}$ 176). Disponível em: <http://bvsms.saude.gov.br/bvs/publicacoes/dengue_aspecto_epidemiologicos_ diagnostico_tratamento.pdf $>$. Acesso: 01 mar. 2016.

MINISTÉRIO DO MEIO AMBIENTE. Programa Nacional de Educação Ambiental - ProNEA. 2014. Disponível em: <http://www.mma.gov.br/images/arquivo/80221/pronea_4edicao_web1.pdf>. Acesso: 01 mar. 2016. 
NARCIZO, K. R. S. Uma análise sobre a importância de trabalhar educação ambiental nas escolas. Revista Eletrônica Mestr. Educ. Ambient., v. 22, p. 86-94, 2009. Disponível em: <https://www.seer.furg.br/remea/article/view/2807/1583>. Acesso: 01 mar. 2016.

OEHLER, E.; WATRIN, L.; LARRE, P.; LEPARC-GOLFRT, I.; LESTÈRE, S.; VALOUR, F.; Baudouin, L.; Mallet, H. P.; Musso, D.; Ghawche, F. Zika virus infection complicated by Guillain-Barré Syndrome: case report, French Polynesia, December 2013. Euro Surveill., v. 19, n. 9, $\quad$ p. 1-3, 2014. Disponível em: $<$ http://www.eurosurveillance.org/images/dynamic/EE/V19N09/art20720.pdf > . Acesso em: 01 mar. 2016.

PINTO, P. S.; PINTO, F. O.; DUARTE, S. C. A dengue e sua relação com Educação Ambiental no Município de Quissamã/RJ. Revista Científica da Faculdade de Medicina de Campos, v. 8, n. 1, p. 14-18, 2013. Disponível em: <http://www.fmc.br/revista/V8N1P14-18.pdf>. Acesso: 01 mar. 2016.

SANTOS-GOUW, A. M.; BIZZO, N. A dengue na escola: contribuições para a educação em saúde da implementação de um projeto de ensino de Ciências. In: ENCONTRO NACIONAL DE PESQUISA EM EDUCAÇÃO EM CIÊNCIAS, 7, Florianopólis, 2009. Disponível em: <http://posgrad.fae.ufmg.br/posgrad/viienpec/pdfs/380.pdf>. Acesso: 01 mar. 2016.

SOUZA, A. K. A relação escola-comunidade e a conservação ambiental. Monografia. João Pessoa, Universidade Federal da Paraíba, 2000. 


\section{Anexo 01}

\section{Questionário da Dengue}

1. Nome: Sexo: F( ) M( ) Idade

\section{Bairro onde mora?}

3. Quantidade de moradores em sua residência?

4. Algum familiar já teve Dengue, chinkungunya ou Zica vírus? Sim ( ) Não ( )

4.1Quantos foram os integrantes diagnosticados?

- Dengue Se sim, foi o caso clássico ou hemorrágico?

- Chinkungunya

- Zica vírus

5. Algum familiar apresentou as três doenças? Sim ( ) Não ( )

5.1Se sim, qual a idade deste (s)?

5.2 Se não, apresentou algum sintoma suspeito as três doenças?

5.3 Houve diagnóstico feito pelo médico? Sim ( ) Não ( ).

5.4 Houve internação? Sim ( ) Não ( ).

6. Quais os primeiros sintomas da doença que foram apresentados?

\section{( )Dengue:}

\section{( ) Chinkungunya:}

\section{( ) Zica vírus:}

7. Fez uso de medicação por conta própria? Se sim, qual?

( ) Paracetamol ( ) Dipirona ( ) Ácido Acetil Salicílico (AAS)

( ) Anti-inflamatório não hormonal ( ) Outras (Qual?)

9. Você sabe identificar o mosquito que transmite dengue, chinkungunya ou zica vírus (Aedes aegypti)?

( ) Corpo de cor escura e com manchas brancas.

( ) Coloração marrom e pernas que não possuem marcação clara.

10. Você já encontrou algum mosquito com de cor preta com manchas (riscos) branca no dorso, pernas e cabeça em sua residência? Sim ( ) Não ( ).

- Isso ocorre com frequência? Sim ( ) Não ( ).

- Sua casa recebe visita do agente de endemias? Sim ( ) Não ( ).

11. Voce sabia que a dengue, a febre chikungunya e o vírus zika são transmitidos através da picada do mosquito Aedes aegypti? ( ) Sim ( ) Não.

12. Você sabe citar sintomas de cada doença?

Dengue:

Sintomas:

Prevenção:

Chinkungunya:

Sintomas:

Prevenção:

Zica vírus: 
Sintomas:

Prevenção:

13. Você sabia que a fêmea do mosquito precisa de água parada para se reproduzir? ( ) Sim ( ) Não.

14. Você sabia que o meio mais SEGURO para combater a dengue, a febre chikungunya e o vírus zika é não mantendo o mosquito Aedes a. por perto? ( ) Sim ( ) Não.

15. O país está mobilizado para o combate da proliferação do mosquito Aedes aegypty. No que diz respeito a ações que previnam a proliferação desse mosquito, você tem contribuído para este combate? ( ) Sim ( ) Não.

\section{Prevenção}

16. Você sabe por que estão surgindo casos de microcefalia? ( ) Sim ( ) Não.

17. Conhece algum caso de microcefalia? ( ) Sim ( ) Não. Se sim, qual a idade da mãe?

18. Consulte se em seu domicílio tem recipientes potenciais para a criação do mosquito. (entulho, pneu, tampinha de garrafa pet, casca de ovo, saco plástico, latinha, vasos, lixo e etc.) Sim ( ) Não ( ) Se sim, quantos?

19. Consulte se no domicilio do seu vizinho tem recipientes potenciais para a criação do mosquito. Sim ( ) Não ( ) Se sim, quantos?

20. No local onde você mora possui algum local com entulho? ( ) Sim ( ) Não. 


\section{Anexo 02}

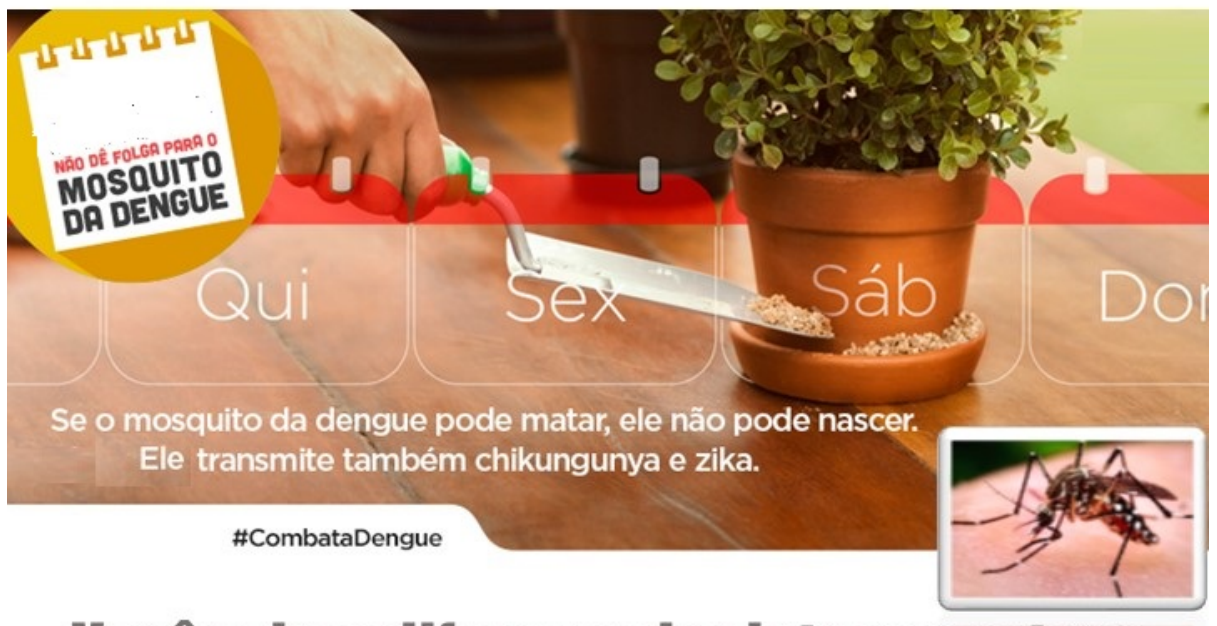

\section{Você sabe a differença de sintomas entrea Dengue, a Chikungunya e o Zika Vírus?}
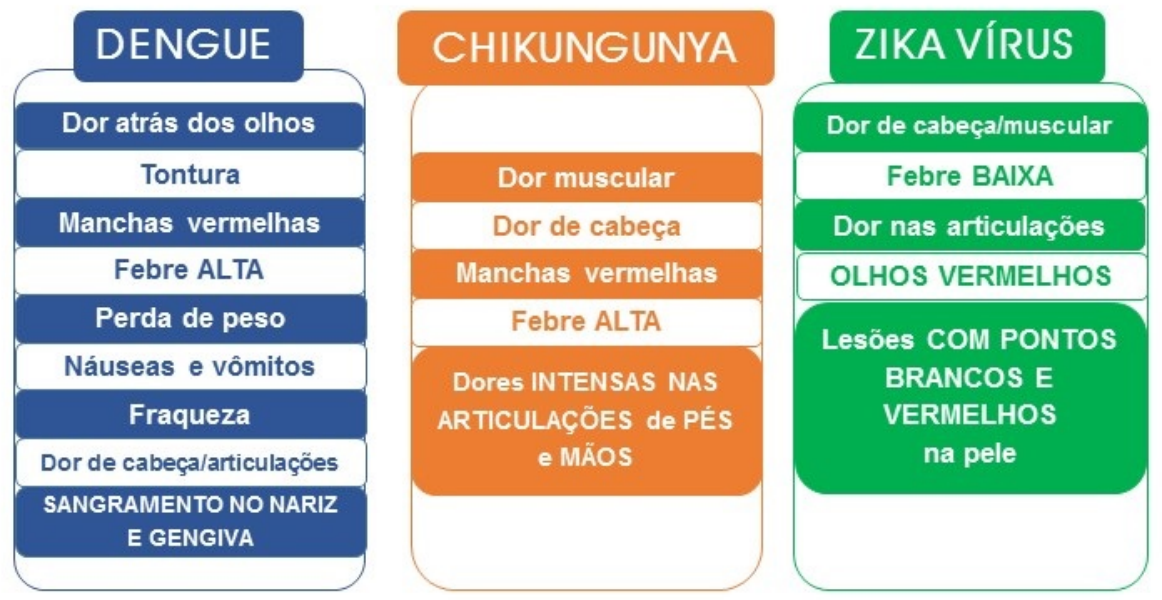